\title{
Herd-level variables associated with delayed milk ejection in Michigan dairy herds
}

\author{
R. Moore-Foster, ${ }^{1}$ B. Norby, ${ }^{1}$ R. L. Schewe,${ }^{2}$ R. Thomson, ${ }^{3}$ P. C. Bartlett, ${ }^{1}$ and R. J. Erskine ${ }^{1 *}$ \\ ${ }^{1}$ Department of Large Animal Clinical Sciences, Michigan State University, East Lansing 48824 \\ 2Department of Sociology, Syracuse University, Syracuse, NY 13244 \\ ${ }^{3}$ Department of Animal Science, Michigan State University, East Lansing 48824
}

\section{ABSTRACT}

The objective of this study was to determine which herd-level variables were associated with delayed milk ejection (bimodal milk let-down) in 64 Michigan dairy herds. Median herd size was 294 cows (range 59 to 2,771 cows). For each herd, milking protocols were observed and milk flow dynamics were estimated by use of digital vacuum recorders. Surveys were also administered to the producers to measure mastitis management practices and attitudes. Milk flow dynamics were recorded for a total of 3,824 cow milkings, with a mean of 60 milkings per herd (range of 11 to 154). Backward multivariable analysis was used to determine which of the 47 herd-level milking and management variables were associated with delayed milk ejection (cows with milk let-down periods between milking cluster attachment and the incline phase of milk flow of $>30 \mathrm{~s}$ ). Delayed milk ejection occurred in an average of $25 \%$ of the cows in each herd (range 0 to $75 \%$ ). A multivariable model found that the proportion of cows in a herd with delayed milk ejection was negatively associated with mean total time of tactile stimulation during premilking routines and positively associated with herd size. Key words: delayed milk ejection, bimodal milking, milking behaviors

\section{INTRODUCTION}

Milk ejection is the active transport of alveolar milk through the milk ducts into the cisternal compartment following contraction of myoepithelial cells that surround the mammary alveoli (Bruckmaier and Wellnitz, 2008). Delayed milk ejection (DME), most often exhibiting as bimodality, is caused by the disturbance of oxytocin availability to myoepithelial cells, which

Received February 8, 2018.

Accepted September 4, 2018.

*Corresponding author: erskine@msu.edu interrupts milk flow between the release of cisternal and alveolar milk (Bruckmaier and Blum, 1996, 1998). Delayed milk ejection has negative health effects for the udder, including penetration of the milking vacuum into the cistern, which can subsequently collapse the teat cavity and interrupt blood flow (Bruckmaier and Wellnitz, 2008). This may, in turn, allow the milking clusters to "climb" up the teats, cause air admission and increase bacterial exposure to the teat ends. This then disrupts effective milk ejection during the remainder of milking, even after DME has been resolved, and is associated with decreased milk yield (Sandrucci et al., 2007; Bruckmaier and Wellnitz, 2008; Samoré et al., 2011).

Several factors have been associated with increased risk of DME. The most common human behavioral factors are inadequate premilking stimulation and improper latency period (Weiss and Bruckmaier, 2005; Sandrucci et al., 2007; Watters et al., 2012). Weiss and Bruckmaier (2005) recommended that the duration of stimulation before milking should be 30 to $60 \mathrm{~s}$. However, with low udder filling, longer stimulation periods of $90 \mathrm{~s}$ can be helpful, although stimulation of $20 \mathrm{~s}$ is still recommended even for udders with a high degree of filling. This amount of stimulation may not be practical in many parlor environments. Other researchers have found that stimulation by stripping before milking did not affect milk flow or yield (Wagner and Ruegg, 2002). Additionally, a minimal latency period between teat stimulation and cluster attachment should be included in the routine to allow oxytocin to attain plasma concentrations that will sufficiently activate myoepithelial cells in the udder (Bruckmaier, 2013). Because of the short plasma half-life of oxytocin, no more than $2 \mathrm{~min}$ should pass between tactile stimulation and milking unit attachment (Bruckmaier, 2013).

Additionally, cow factors such as increasing DIM may also contribute to DME. According to Sandrucci et al. (2007), the percentage of milk flow curves with DME increases in later lactation; $27 \%$ of cows $<150$ DIM and $41 \%$ of cows $>150$ DIM had delayed milk flow curves. This agrees with Kaskous and Bruckmaier (2011), who 
found a higher proportion of DME in cows with less alveolar filling of milk before milking compared with cows with greater levels of alveolar filling - a factor typical of cows milked more frequently per day or in late lactation.

As herd size increases in the US dairy industry, farms are increasingly reliant on hired labor versus traditional owner-family labor (Baker and Chappelle, 2012; von Keyserlingk et al., 2013). Sandrucci et al. (2007) found that as farm size increases, less time is spent on proper teat stimulation, therefore reducing time for udder preparation. However, beyond herd size and teat stimulation, other variables such as latency period, frequency of milking, work load of the operators (e.g., the number of units per operator and the cows milked per operator per hour), and employee turnover rate may also affect milk ejection. The purpose of this study was to explore the association of a wide scope of behavior-related variables on DME and the relative importance of these associations compared with previously identified factors such as teat stimulation.

\section{MATERIALS AND METHODS}

\section{Dairy Farm Selection}

This study was part of a larger project in which 124 dairy herds in Florida, Michigan, and Pennsylvania participated in a 15-mo trial to develop an evaluation to assess mastitis and antimicrobial drug use. The 64 Michigan dairy herds that were part of this larger study were visited by investigators twice between January 2016 and May 2017. Enrolled herds participated in the DHI individual-cow SCC option and had a herd size $\geq 70$ cows. Because the overall objectives of the umbrella project included employee-related factors on milk quality and antimicrobial use on dairy farms, organic dairies and herds that milked with automated milking systems were excluded. All survey information was collected following approval and performed within the guidelines set by the Institutional Review Board of Michigan State University.

\section{Herd Profile and Management Culture}

During the initial herd visit, project investigators explained the study design and conducted a herd profile to record milking times and groups, type of milking facility, housing, employee structure, and other general information. Within 30 to $60 \mathrm{~d}$, the investigators returned to conduct a milk quality evaluation that included (1) milking behaviors and proficiency, (2) milking systems, (3) cow environment, (4) monitoring and therapy of infected cows, and (5) farm manage- ment culture. To capture information relative to the management culture, we interviewed dairy producers or managers with an 84-question survey relative to their mastitis control practices, attitudes, and behaviors (Schewe et al., 2015). Additionally, a separate 16-question human resources survey was administered to describe producer or manager beliefs and practices regarding employee communication, training, and education. Approximately $90 \mathrm{~min}$ was needed to conduct the surveys and review the project with each producer.

\section{Milking Dynamics and Parlor Behaviors}

We evaluated milking vacuum by using VaDia digital recorders (Biocontrol, Rakkestad, Norway). Four vacuum channels were used for each individual cow evaluation by attaching 2.4-mm (internal diameter) silicon tubing to the following positions on the milking cluster: (1) rear quarter liner mouthpiece to record vacuum in the mouthpiece chamber (MPC), (2) front quarter liner mouthpiece to record MPC vacuum, (3) short milk tube (SMT) as a proxy for cluster vacuum, and (4) short pulsation tube to record pulsation. Previous recordings by the investigators from 40 cows had demonstrated the consistency between simultaneous vacuum recordings in the short milk tube and actual cluster vacuum by insertion of a needle into the bowl of the cluster (not reported).

Each cow-milking event was continuously recorded from the time that milking units were attached until units were removed, either automatically by milk flow sensors or manually by employees. We identified 4 phases of flow intensity: incline, plateau, decline, and overmilking, as described by Tančin et al. (2007), for our interpretive guidelines and determined the following phases for our study: start of milking, start of the incline phase of milk flow, start of overmilking (end of the decline phase and near static levels in the SMT and MPC vacuum), and end of milking. All vacuum recordings were downloaded and reviewed using the VaDia Suite software (Biocontrol) by 2 investigators (Moore-Foster and Erskine), and interoperator agreement of interpretation was tested in 6 herds before the beginning of the trial and found to be better than $98 \%$. We interpreted our vacuum data using the principle that milk vacuum in the cluster is the inverse of milk flow, as suggested by Schukken et al. (2005). More recently, Penry et al. (2018) determined that increasing MPC vacuum is also associated with lower milk flow as a consequence of teat-end congestion.

For each cow, the start of the incline phase was marked when the vacuum level in at least 1 of the 2 MPC channels decreased to $<13.5 \mathrm{kPa}(4 \mathrm{inHg})$ and the SMT vacuum decreased from maximum and fluctu- 
ated by $\geq 3.4 \mathrm{kPa}(1 \mathrm{inHg})$. The time interval between the start of milking (cluster attachment) and the start of the incline phase was then calculated and termed by the VaDia software as "let-down time" (LDT). The end of milking was determined to occur when vacuum returned to $0 \mathrm{kPa}$. (Figure 1 ). We defined cows with an LDT of $>30 \mathrm{~s}$ as having DME and those with a LDT of $\leq 30 \mathrm{~s}$ as having normal milk ejection. This cut-off for DME was based on an initial scatterplot of LDT versus the duration of unit attachment ("milking time"; Figure 2) and distribution of LDT for all cows in the study (Figure 3). Thus, DME was analyzed as a dichotomous variable. Bimodal milk ejection (example in lower plot of Figure 1) was not observed for any cows that had an LDT of $\leq 30$ s. Conversely, $96 \%$ of cows with an LDT $>30$ s demonstrated bimodal milk ejection, and the remaining $4 \%$ of the cows in this category demonstrated high MPC vacuum and low SMT vacuum fluctuations (indicative of low milk flow) for a period of time despite a lack of an initial drop in vacuum after cluster attachment (indicative of bimodality).

During the vacuum analysis for each herd, the quality of air hoses, liner alignment, and air vent patency were also recorded. System vacuum capacity was also tested with a "unit fall off test"; and results determined according to National Mastitis Council standards (National Mastitis Council, 2012).

In addition to the VaDia and cluster evaluation, we observed milking procedures and protocols to determine the milking routine, the latency period, and time of tactile stimulation of teats. A minimum of 4 milking strings (defined as one side of a parlor) were recorded during milking preparation in parlors. In platform or tie-stall milking operations, stimulation and latency periods were recorded for at least 4 cows per unit. When more than one person was milking, milking behaviors were observed for at least 2 milking strings for each person.

\section{Parlor Ergonomics}

Measures of parlor ergonomics were estimated by determining the width of the parlor workspace, the height from the floor to the platform, light availability, duration of a milking shift, and the availability of breaks during the shift. Lighting in the parlor was measured with a light meter, both in the middle of the parlor floor (mean of 3 separate locations) and at the level of the teat, under the cow (mean of 6 to 10 locations, depending on the number of milking units). Additionally, for parallel, herringbone, and side in/side out parlors, we measured the length of the parlor floor to derive an estimate of the minimum linear distance that each person milking cows might travel during a milking shift (tie-stall milking systems were excluded). This was calculated by using the following formula:

Total distance per shift $=(\mathrm{D} \times \mathrm{PTR}) \times \mathrm{T}$,

where $\mathrm{D}=$ distance each employee traveled per parlor load (both sides of the parlor) of cows (m/load), PTR $=$ parlor turnover rate, or number of milking loads in the parlor per hour (loads/h), and $\mathrm{T}=$ shift length (h).

The distance each employee traveled for each parlor load (D) was estimated by measuring the length of the parlor floor multiplied by the proportion of stalls that each employee visited during each pass of the milking routine. This distance was then multiplied by the number of passes in the routine for both sides of the parlor and then doubled (to account for forward and reverse direction for each pass).

The formula for total distance $(\mathrm{m})$ each employee traveled per load of cows (D) was

$$
\mathrm{D}=(\mathrm{L} \times \mathrm{P} \times \mathrm{N}) \times 2^{\mathrm{a}} \times 2^{\mathrm{b}},
$$

where $\mathrm{L}=$ length of parlor $(\mathrm{m}), \mathrm{P}=$ proportion of stalls prepared by employee, $\mathrm{N}=$ number of premilking passes per cow, $2^{\mathrm{a}}=$ factor to account for forward and reverse direction between passes, and $2^{\mathrm{b}}=$ factor to account for duplication of distance for each side of parlor per load of cows. For example, if one employee milked in a parlor with 20 stalls (10 cows per side) with a 10-m-long parlor, and 3 separate passes were made for each cow during preparation or cluster attachment, then

$$
\mathrm{D}=10 \mathrm{~m}(\mathrm{~L}) \times 1.0(\mathrm{P}) \times 3(\mathrm{~N}) \times 2 \times 2=120 \mathrm{~m} .
$$

\section{Statistical Analysis}

Dependent Variable. The dependent variable for this study was the proportion of VaDia-evaluated cows with DME in each herd. The proportion of cows with DME was entered into Excel (Microsoft Corp., Redmond, WA) for data management, and SAS software (ver. 9.4; SAS Institute Inc., Cary, NC) was used for descriptive and analytical analyses.

Independent Variables. The independent variables were divided into 3 categories: (1) management culture and human resources, (2) employee behaviors, and (3) parlor factors. Management culture and human resource variables included milking technician turnover rates (defined as number of milking technicians hired per year divided by number of positions available), as well as survey questions that included frequency of employee training, manager attitudes about parlor 
turnover rates, and how often managers communicated with employees on personal matters. The average pay rate and other benefits were also included, if applicable. Employee behaviors included mean total stimulation time, latency period, distance traveled per shift, number of stalls per pass, and parlor flow rates (described as cows milked per hour, cows milked per employee per hour, and milking strings per hour). Parlor factors included rail height, light intensity, frequency of milking per day, if $95 \%$ of liners were properly aligned within the cluster (yes $=1$, no $=0$ ), and if $95 \%$ of air vents on the cluster were open (yes $=1$, no $=0$ ).
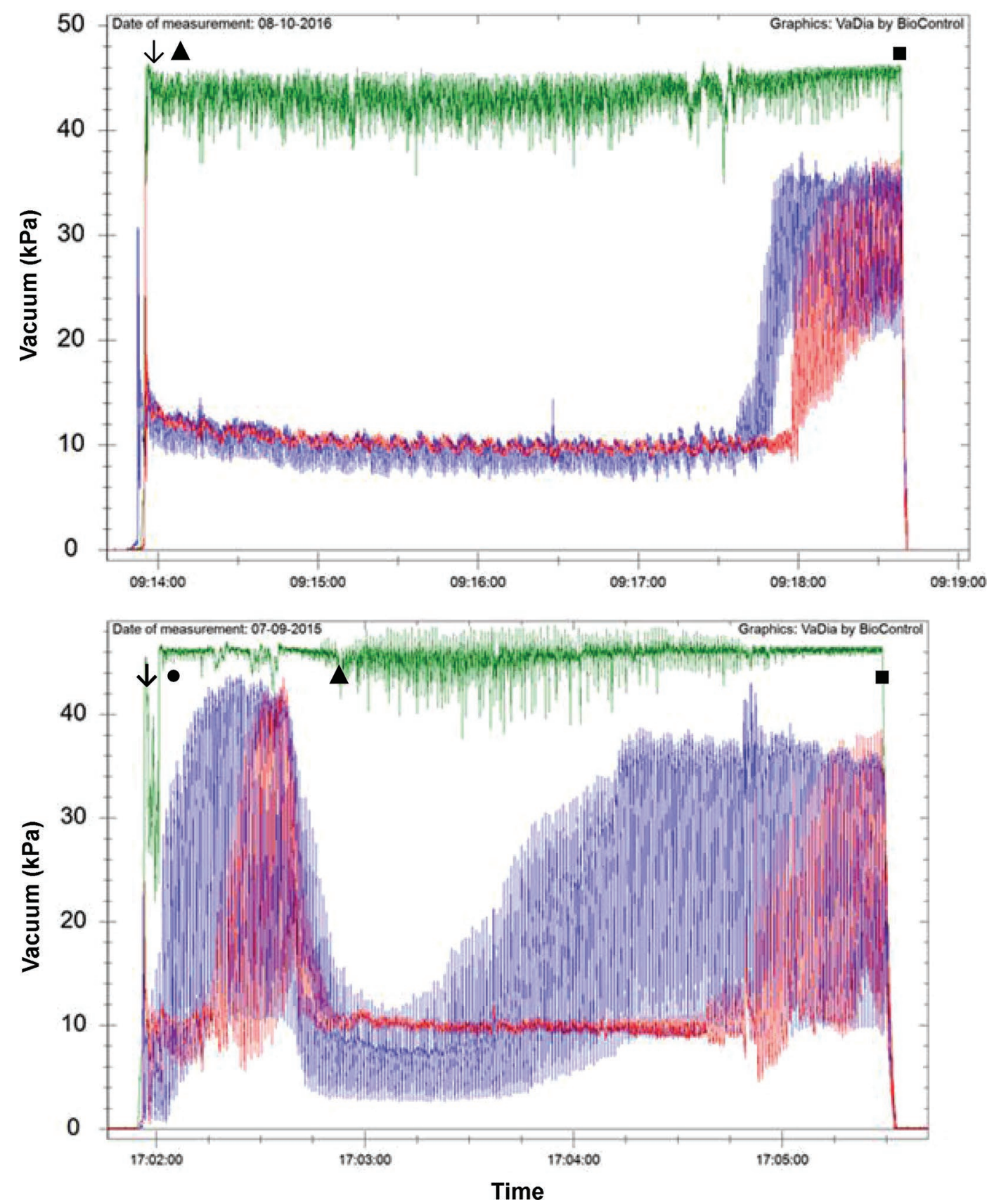

Figure 1. Examples of VaDia (Biocontrol, Rakkestad, Norway) digital recordings showing uninterrupted milk ejection (top) and bimodal milk ejection (bottom). Vacuum is recorded $(\mathrm{kPa})$ on the vertical axis. Each hash mark indicates a 30-s time interval on the horizontal axis (top) or a 15-s time interval on the horizontal axis (bottom). Channel 1 (red) = rear mouthpiece chamber vacuum, channel 2 (blue) $=$ front mouthpiece chamber vacuum, and channel 3 (green) = short milk tube vacuum. Symbols mark the start of milking ( $\downarrow$ ), start of bimodal ejection $(\bullet)$, start of incline phase of milk flow $(\boldsymbol{\Lambda})$, and end of milking $(\boldsymbol{\square})$. 
Scale Factor Analysis. Initially, a frequency distribution was graphed for each independent variable in our model and normality was checked for continuous variables by visually inspecting the results of residual analysis and ANOVA. Scales were constructed with 3 to 5 variables that researchers deemed most relevant. Three scales were tested that accounted for premilking procedures, management attitudes, and parlor flow. However, only the premilking procedures scale met the criteria for further analysis (Eigenvalue $>1$ and Cronbach's $\alpha>0.7$ ), which included 3 variables: mean time of stimulation at first touch, mean total time of tactile stimulation (natural log transformation), and average latency period (Eigenvalue $=2.04$ and Cronbach's $\alpha$ $=0.75)$.

Bivariate Analysis. To decide which independent variables were eligible for the multivariable analysis, associations between the proportion of DME in a herd and explanatory continuous variables were investigated using Pearson's product-moment correlation coefficient. For binary (nominal) variables, the dependent variable was compared with the independent variables using a Chi-squared goodness-of-fit test. Any variables with an initial cutoff of $P<0.20$ (2-tails) were considered eligible for inclusion in the multivariable model.

Multiple Linear Regression. We used 5 different modeling approaches to build the final multivariable regression model until only significant variables $(P<$ $0.05)$ were retained using a type-III $F$-test: $(1)$ automated forward regression, (2) automated backward regression, (3) automated stepwise regression, (4) manual forward stepwise regression, and (5) manual backward stepwise regression. Because of the large number of interaction terms (36) for models with the 9 main effects, only biologically relevant 2 -way interaction terms between herd size and mean stimulation time (natural $\log$ ) were tested in any of the models. In separate models, covariates with $P$-values between 0.05 and 0.1 were retained during modeling procedures. Herd size was also analyzed as a confounder and was found to change the coefficients and coefficient of determination values by more than $10 \%$ for mean time of tactile stimulation. Thus, herd size was included as a confounder in the model. The residual distribution was assessed visually for normality and similar variances.

\section{RESULTS}

Median herd size was 294 milking cows and ranged from 59 to 2,771 cows (Table 1). Mean daily milk per milking cow was $36.8 \mathrm{~kg}$, the 3 -mo DHI geometric mean SCC was 136,800 cells/mL, and $62 / 64$ herds $(97 \%)$ employed nonfamily labor. This was representative of DHI data for herds in Michigan during 2016; mean herd size

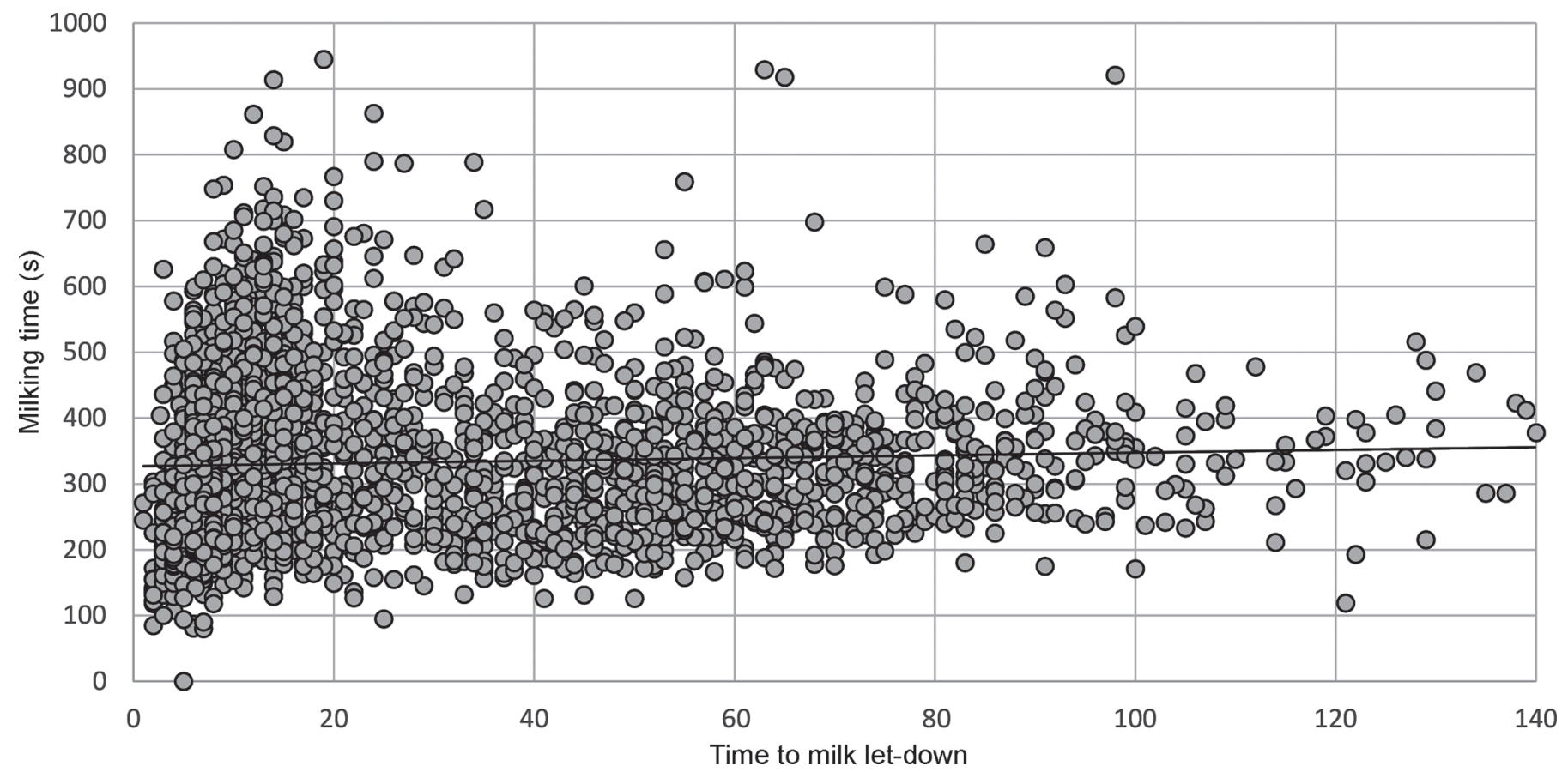

Figure 2. Scatterplot of time period between cluster attachment and attaining the incline phase of milk ejection (time to milk let-down) versus duration of time that the milking cluster was attached (milking time) for 3,824 cows as recorded by digital vacuum ( $\mathrm{R}^{2}=0.002$ ). 


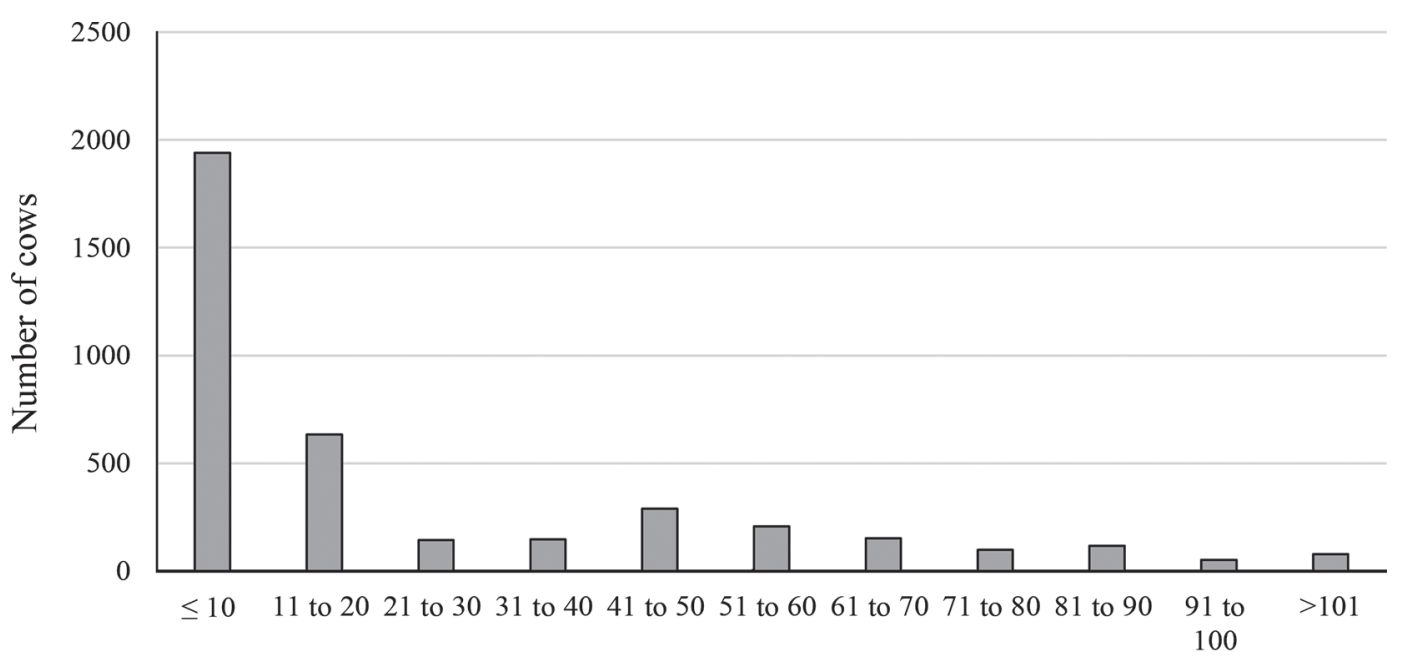

Time to milk let-down (s)

Figure 3. Histogram of time period between cluster attachment and attaining the incline phase of milk ejection (time to milk let-down) for 3,824 cows as recorded by digital vacuum.

was reported to be 257 cows, mean daily milk $37.8 \mathrm{~kg}$, and mean SCC 157,000 cells/mL (Norman et al., 2017). A total of 3,824 cows (mean of $60 \pm 29$ recordings per herd) were evaluated by VaDia analysis, which averaged $23.5 \%$ of the milking herd. The mean percentage of cows with DME was 25.0\% (Table 1; 95\% CI: 20.1 to $30.0 \%$ ). Mean time of stimulation during the first premilking pass was $8.0 \mathrm{~s}(95 \% \mathrm{CI}: 6.6$ to $9.3 \mathrm{~s})$ and mean total stimulation time was $14.2 \mathrm{~s}$ (95\% CI: 11.9 to $16.5 \mathrm{~s}$ ). Mean latency period, from first stimulation to cluster attachment, was 103 s (95\% CI: 96 to 111 s). Recording flaws (e.g., tubes that were disconnected during milking, milking clusters that fell off the udder during milking and were reattached, battery failure) resulted in less than $5 \%$ of the VaDia recordings; cows with these events could not be accurately assessed for milk flow dynamics relative to DME and were excluded.

Based on the bivariable analysis, 28 variables met the $P<0.20$ criterion; however, to facilitate the model, we selected 9 variables with the lowest $P$-values and that were most likely to be relevant to milk ejection physiology for multivariate analysis based on the following categories: (1) herd characteristics, (2) employees, (3) parlor, and (4) premilking procedures. Herd size (natural log; $P<0.001)$, frequency of milkings per day $(P$ $=0.06)$, number of milking stalls $(P<0.001)$, milking shift length $(P=0.006)$, cows milked per full time employee-hour $(P=0.005)$, number of cows milked per hour (natural log; $P=0.008$ ), mean latency period $(P$ $=0.008$ ), mean stimulation time (natural log-transformation; $P<0.001)$, and mean light illumination in the parlor $(P=0.026)$ were all included in the multivariate analysis.
Each of the 5 model strategies resulted in the same main effects being included in the final models. The final multivariable model found total mean stimulation time (natural $\log$ ) to be negatively and herd size (natural $\log$ ) to be positively associated with the proportion of cows with DME in a herd (Table 2).

Because herd size was retained in the final model, we performed a 2-sample $t$-test to compare means for each of the eligible variables, stratified by herd size, to better understand if exclusion of some of the eligible variables could be explained by association with herd size (Table 3$)$. The cut-off point selected for large $(\geq 300$ cows; natural $\log [300]=5.70)$ and small $(<300$ cows) dairies was based on the criteria that we used for the umbrella project of the present study (Schewe et al., 2015). Other than milking frequency, mean latency period, and illumination, means for all other variables differed $(P<0.05)$ between small and large herds. Total stimulation time in smaller herds $(19.2 \mathrm{~s})$ was more than twice that of larger herds (8.8 s; natural $\log [8.8]$ $=2.17$ ). The effect of stimulation time on DME was tested for an interaction with herd size, but had a $P$ $=0.67$.

\section{DISCUSSION}

Our intent was to determine which herd variables, and their estimated relative importance, may influence the extent of DME in dairy herds. The 64 herds in this study had a mean geometric SCC below the US and Michigan DHI average. Even among this population of herds, we found that, on average, $25 \%$ of cows had delayed milk flow after cluster attachment, which was 


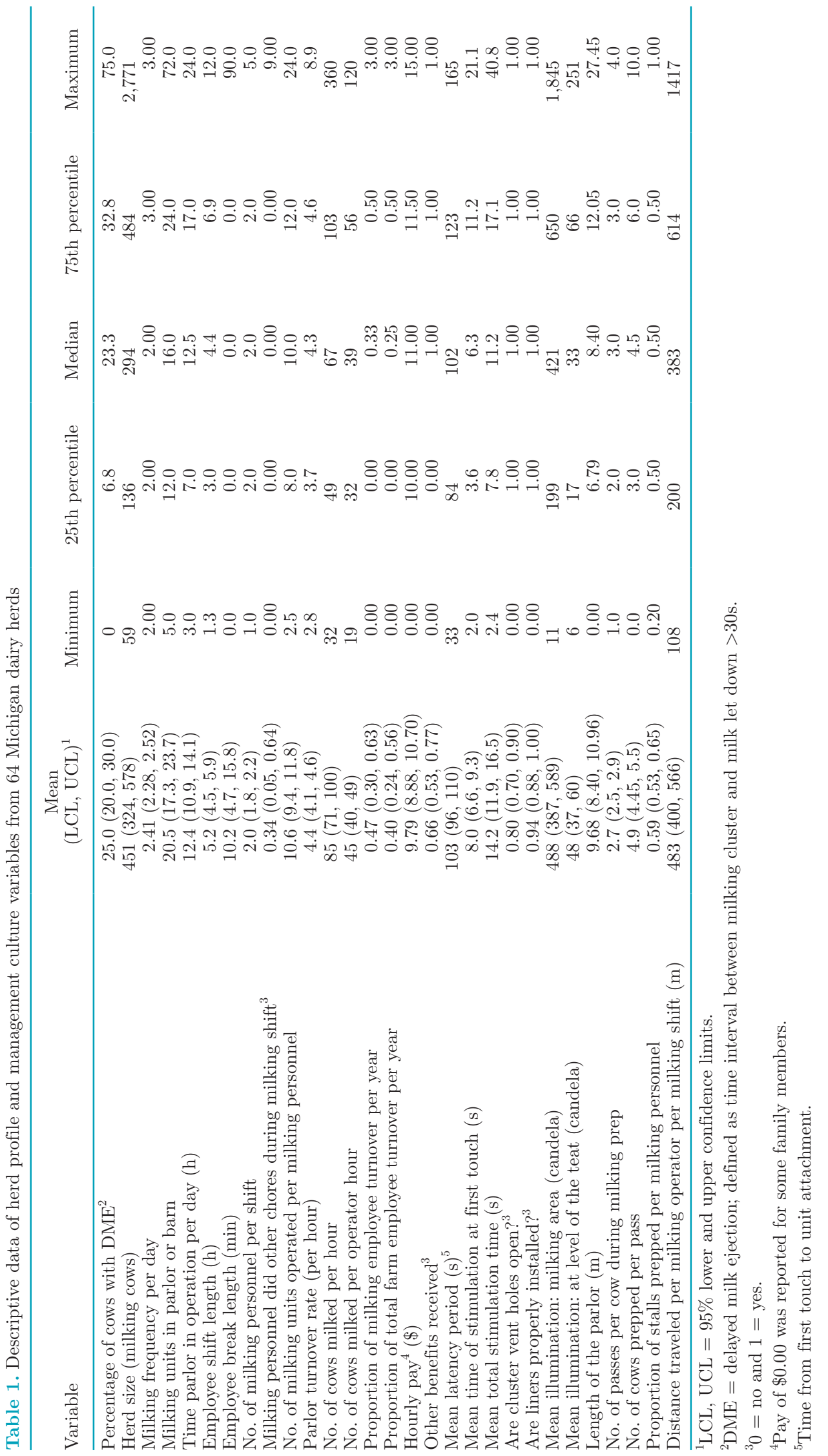


Table 2. Final linear model for associations between delayed milk ejection and herd-level variables in 64 Michigan dairies

\begin{tabular}{lccrc}
\hline Parameter & Estimate & $\mathrm{SE}$ & $P$-value & $\mathrm{R}^{2}$ \\
\hline Intercept & 4.32 & 2.38 & 0.074 & 0.36 \\
Mean total stimulation time (natural log) & -1.30 & 0.43 & $<0.005$ & \\
Herd size (natural log) & 0.599 & 0.28 & 0.034 & \\
\hline
\end{tabular}

similar to past research that reported the proportion of cows with DME to be between 22 and $35 \%$ (Sandrucci et al., 2007; Samoré et al., 2011).

In our study, herds that stimulated teats for a longer duration of time had a lower proportion of cows with DME. This is similar to previous literature that also found premilking stimulation to be an important precursor for oxytocin release to induce milk ejection (Weiss and Bruckmaier, 2005), and increased stimulation is associated with decreased bimodal milk ejection (Bruckmaier, 2013). Additionally, Watters et al. (2015) reported that the frequencies of bimodal milking among cows that had clusters attached immediately, attached after dipping and forestripping followed by a 30-s latency period, or attached after dipping and forestripping followed by a 90-s latency period were 21 , 14 , and $7 \%$, respectively. In a study that was similar in size to ours (nearly 2,500 cows), Sandrucci et al. (2007) reported that bimodal milk ejection decreased from $47 \%$ for cows with no udder preparation to $30 \%$ for cows that were cleaned and forestripped. As much as $60 \mathrm{~s}$ of stimulation has been suggested for efficient milk ejection, but stimulation of at least $15 \mathrm{~s}$ can induce milk ejection if a latency period of at least $45 \mathrm{~s}$ is included (Weiss and Bruckmaier, 2005; Kaskous and Bruckmaier, 2011; Bruckmaier, 2013). These goals were similar to the mean total stimulation time $(14.2 \mathrm{~s})$ and latency period (103 s) observed in our study. However, the duration of both stimulation and latency period may not be as critical for efficient milk ejection in cows that have greater udder filling at milking, such as cows in early compared with later lactation (Kaskous and Bruckmaier, 2011).

Milking frequency effects on udder filling may help explain why our results are in contrast to those of Wagner and Ruegg (2002), who found that stripping teats before milking was not associated with milk flow rates, milk yield, or unit-on times. However, in that study, only 24 multiparous cows from one farm were included and were milked twice per day. Thus, if udder filling is greater in cows milked twice per day, the potential impact of teat stimulation on DME may be reduced in herds that milk less frequently. Furthermore, in the Wagner and Ruegg (2002) study, both groups of cows (pre-stripped and not pre-stripped) were vigorously dried with towels for 10 to $15 \mathrm{~s}$ just before cluster attachment. In our study, we had considerable diversity in milking systems and protocols, and $41 \%$ of herds ( 26 of 64) were milked 3 times per day. Thus, our project may have offered a broader scope of variables that need to be considered in the relationship between stimulation and DME.

Sandrucci et al. (2007) found that as farm size increased, less time was spent on teat stimulation, thus reducing time for udder preparation. Our study also found that larger herds had decreased time of stimulation; total stimulation time in smaller herds was more than twice that of larger herds. Conversely, the length of a work shift, the number of cows that were milked per employee-hour, and the number of milking units each employee operated during the milking routine were greater in larger herds. The increased workload of

Table 3. Comparison of means for eligible independent variables for multivariable model between small $(<300$ cows) and large herds ( $\geq 300$ cows $)$ in 64 Michigan dairy herds

\begin{tabular}{|c|c|c|c|}
\hline \multirow[b]{2}{*}{ Variable } & \multicolumn{2}{|c|}{ Mean (SEM) } & \multirow[b]{2}{*}{$P$-value } \\
\hline & Small herds & Large herds & \\
\hline Milking frequency per day & $2.47(0.09)$ & $2.33(0.09)$ & 0.27 \\
\hline No. of milking units & $13.47(0.96)$ & $26.70(2.50)$ & $<0.05$ \\
\hline Employee (operator) shift length (h) & $3.52(0.27)$ & $6.82(0.46)$ & $<0.05$ \\
\hline Cows milked per full-time employee hour (natural log) & $3.58(0.06)$ & $3.85(0.07)$ & $<0.05$ \\
\hline Units operated per employee & $8.67(0.50)$ & $12.35(0.94)$ & $<0.05$ \\
\hline Mean latency period $(\mathrm{s})$ & $110.0(5.70)$ & $96.90(4.70)$ & 0.08 \\
\hline Mean total stimulation time (s, natural log) & $2.82(0.10)$ & $2.16(0.09)$ & $<0.05$ \\
\hline Mean illumination in parlor (candela) & $396(73)$ & $564(68)$ & 0.10 \\
\hline
\end{tabular}


employees in larger herds compared with smaller herds suggests there may be more emphasis on cow throughput in larger dairies. Intriguingly, the data in Figure 2 suggest that there is no correlation between time to milk let-down (as measured qualitatively by VaDia) and the duration of time the unit is on the cow (milking time). This seems counterintuitive because a cow with DME would seemingly need to compensate with a longer milking time to fully release all her milk during a milking. Penry et al. (2018) suggested that high vacuum on the teat, typical of periods of bimodality, may decrease the teat canal diameter and impede milk flow. Taken together, these results suggest that larger herds may be sacrificing milking efficiency, as defined by the proportion of time that a cow is releasing milk while the cluster is attached, and possibly milk yield, for greater cow throughput.

Additionally, larger dairies have more complex employee structures, and many dairies report difficulty in training and maintaining protocols, which is associated with higher bulk tank SCC (Erskine et al., 2015; Schewe et al., 2015). This problem could be exacerbated in herds that have a protocol culture that leads to a higher proportion of cows with DME.

Surprisingly, we did not find an association between DME and latency period between preparation and cluster attachment. Previous reports found that latency periods are a key factor in reducing bimodal milk flow and improving overall milking time efficiency (Weiss and Bruckmaier, 2005; Watters et al., 2012). Additionally, the frequency of bimodal milk ejection among cows without a lag interval was $54 \%$, but decreased to 36 and $24 \%$ for cows with latency periods of $<60$ s and $\geq 60$ s, respectively (Sandrucci et al., 2007). However, in our study herds, the mean latency period across all herds was within the suggested goal for efficient milk ejection, and the minimum was $33 \mathrm{~s}$. Thus, the overwhelming proportion of herds had a latency period that was likely sufficient to augment oxytocin-induced milk ejection, which could have masked the importance of this variable in our model. In contrast, the range of variation in teat stimulation was nearly 20 -fold across herds, which allowed for greater discrimination of comparisons among our study herds. Past research has also suggested an overriding effect of teat stimulation relative to other factors (Weiss and Bruckmaier, 2005; Ambord and Bruckmaier, 2009). Thus, the more critical question raised from this study may be why some herds attain more stimulation than others.

This study had several limitations; for example, our inability to reliably evaluate vacuum dynamics in cows that had a milking cluster fall off during milking. Some of these interruptions in milking might be related to
DME. However, the proportion of these events was low relative $(<5 \%)$ to the total number of cows evaluated and, in most instances, determining the time points of the milking vacuum curve that included a detached milking unit was deemed to be highly subjective.

To our knowledge, this is the largest study that has used vacuum recordings rather than an electronic milk flow meter as an indicator for milk flow dynamics. Despite this extrapolation between vacuum and milk flow, the distinct partitioning of cows that began the start of the incline phase of milking either $\leq 30 \mathrm{~s}$ or those that were distributed $>30 \mathrm{~s}$ was remarkable when reviewing the scatterplot in Figure 2 and the histogram in Figure 3. Our dichotomous criteria for DME attained very similar results in terms of the proportion of milkings that resulted in delayed LDT and bimodal ejection in previous studies (Sandrucci et al., 2007; Samoré et al., 2011) and the association between stimulation and DME.

The sample size of cows within each herd depended on herd size, milking shift length, and cow throughput while milking. In smaller herds (milking shifts less than $4 \mathrm{~h}$ ), we were present throughout the entire milking. However, especially in larger herds, it was difficult to evaluate all milking groups of cows across all employee shifts. Thus, in herds with short intervals between milking shifts, we recorded milking events in portions of 2 consecutive shifts to gain a wider perspective of milking behaviors. Also, we attached VaDia recorders to several milking clusters in each herd to capture any variation resulting from milking position among cows. Finally, numerous individual cow factors such as stage of lactation, genetics, teat anatomy, and parity have been reported to influence milk ejection, which were not accounted for in our herd-level analyses.

One interesting finding that was tangential to our study objectives was that there was virtually no correlation between LDT and milking time (Figure 2). We constructed this plot to obtain an initial perspective of the distribution of LDT as measured by VaDia recorders. With increasing LDT, and thus duration of DME, we expected a positive correlation between LDT and milking time; however, this was not the case. This raises questions regarding the ability of cows with DME to milk effectively because they would either need to compensate with a faster flow of milk in a shorter time period, or not completely release their milk during the milking. The latter may be more probable, considering the work of Penry et al. (2018), who determined that higher MPC vacuum, typical of DME, results in deceased teat canal diameter and lower milk flow. Further study of this finding may elucidate whether decreased milk harvest is a consequence of DME. 


\section{CONCLUSIONS}

Decreasing the amount of stimulation during the premilking routine was the most critical factor that increased the likelihood of DME in dairy herds. Increased frequency of DME was also more likely as herd size increased. Although other variables were found to be associated with DME from bivariate analysis, the low level of variation among herds for some variables such as latency period, or the effect that herd size may have on other variables, might have masked the contribution of these variables in our multivariable model. Given the strength of the relationship between teat stimulation and DME in our model, further research should investigate the herd-level factors that are associated with teat stimulation.

\section{ACKNOWLEDGMENTS}

This project was supported by Agriculture and Food Research Initiative Competitive Grant no. 2013-6800420439 from the USDA National Institute of Food and Agriculture (Washington, DC). The authors acknowledge participating dairy producers and their employees for their willingness to aid in data collection. Also, the authors thank Leah Girard, Ellen Launstein, Caitlin McNichols, and Trevor Walling (Department of Large Animal Clinical Sciences, East Lansing, MI) for their technical assistance.

\section{REFERENCES}

Ambord, S., and R. M. Bruckmaier. 2009. Milk flow-controlled changes of pulsation ratio and pulsation rate affect milking characteristics in dairy cows. J. Dairy Res. 76:272-277.

Baker, D., and D. Chappelle. 2012. Health status and needs of Latino dairy farmworkers in Vermont. J. Agromedicine 17:277-287.

Bruckmaier, R. M. 2013. Oxytocin from the pituitary or from the syringe: Importance and consequences for milking machine in dairy cows. Pages 4-11 in Proc. 52nd Annu. Mtg. Natl. Mastitis Counc., San Diego, CA. Natl. Mastitis Counc. Inc., New Prague, MN.

Bruckmaier, R. M., and J. W. Blum. 1996. Simultaneous recording of oxytocin release, milk ejection and milk flow during milking of dairy cows with and without prestimulation. J. Dairy Res. 63:201208.

Bruckmaier, R. M., and J. W. Blum. 1998. Oxytocin release and milk removal in ruminants. J. Dairy Sci. 81:939-949.
Bruckmaier, R. M., and O. Wellnitz. 2008. Induction of milk ejection and milk removal in different production systems. J. Anim. Sci. $86: 15-20$.

Erskine, R. J., R. O. Martinez, and G. A. Contreras. 2015. Cultural lag: A new challenge for mastitis control on dairy farms in the United States. J. Dairy Sci. 98:8240-8244.

Kaskous, S., and R. M. Bruckmaier. 2011. Best combination of prestimulation and latency period duration before cluster attachment for efficient oxytocin release and milk ejection in cows with low to high udder-filling levels. J. Dairy Res. 78:97-104.

National Mastitis Council. 2012. Procedures for Evaluating Vacuum Levels and Air Flow in Milking Systems. 2004 rev. ed. Natl. Mastitis Counc., New Prague, MN.

Norman, H. D., L. M. Walton, and J. Dürr. 2017. Somatic cell counts of milk from Dairy Herd Improvement herds during 2016. Council on Dairy Cattle Breeding. Accessed Oct. 3, 2018. https://queries .uscdcb.com/publish/dhi/current/sccx.html.

Penry, J. F., J. Upton, S. Leonardi, P. D. Thompson, and D. J. Reinemann. 2018. A method for assessing liner performance during the peak milk flow period. J. Dairy Sci. 101:649-660.

Samoré, A. B., S. I. Román-Ponce, F. Vacirca, E. Frigo, F. Canavesi, A. Bagnato, and C. Maltecca. 2011. Bimodality and the genetics of milk flow traits in the Italian Holstein-Friesian breed. J. Dairy Sci. 94:4081-4089.

Sandrucci, A., A. Tamburini, L. Bava, and M. Zucali. 2007. Factors affecting milk flow traits in dairy cows: Results of a field study. J. Dairy Sci. 90:1159-1167.

Schewe, R. L., J. Kayitsinga, G. A. Contreras, C. Odom, W. A. Coats, P. Durst, E. P. Hovingh, R. O. Martinez, R. Mobley, S. Moore, and R. J. Erskine. 2015. Herd management and social variables associated with bulk tank somatic cell count in dairy herds in the eastern United States. J. Dairy Sci. 98:7650-7665.

Schukken, Y. H. P., D. Nydam, and D. E. Baker. 2005. Using milk flow curves to evaluate milking procedures and milk equipment. Pages 139-146 in Proc. Natl. Mastitis Coun. 44th Annu. Mtg., Orlando, FL. Natl. Mastitis Counc. Inc., New Prague, MN.

Tančin, V., A. H. Ipema, and P. Hogewerf. 2007. Interaction of somatic cell count and quarter milk flow patterns. J. Dairy Sci. 90:22232228.

von Keyserlingk, M. A., N. P. Martin, E. Kebreab, K. F. Knowlton, R. J. Grant, M. Stephenson, C. J. Sniffen, J. P. Harner 3rd, A. D. Wright, and S. I. Smith. 2013. Invited review: Sustainability of the US dairy industry. J. Dairy Sci. 96:5405-5425.

Wagner, A. M., and P. L. Ruegg. 2002. The effect of manual forestripping on milking performance of Holstein dairy cows. J. Dairy Sci. 85:804-809.

Watters, R. D., R. M. Bruckmaier, H. M. Crawford, N. Schuring, Y. H. Schukken, and D. M. Galton. 2015. The effect of manual and mechanical stimulation on oxytocin release and milking characteristics in Holstein cows milked 3 times daily. J. Dairy Sci. 98:1721-1729.

Watters, R. D., N. Schuring, H. N. Erb, Y. H. Schukken, and D. M. Galton. 2012. The effect of premilking udder preparation on Holstein cows milked three times daily. J. Dairy Sci. 95:1170-1176.

Weiss, D., and R. M. Bruckmaier. 2005. Optimization of individual prestimulation in dairy cows. J. Dairy Sci. 88:137-147. 